\title{
NASA's Mars plans revitalized by Europe
}

[WASHINGTON] Increased European participation and new technical approaches are set to revitalize US plans for exploring Mars, which had been showing signs of becoming stalled by cost overruns and engineering difficulties, according to US officials. The new approach will transform NASA's plans for the exploration of Mars into a fullyfledged joint venture with overseas partners, say the officials.

NASA's decision in late spring to drop a long-distance rover from its planned 2001 Mars mission signalled that the agency's strategy to visit the planet roughly every two years and begin collecting samples in 2001 was starting to unravel. The rover had been designed to wander up to 100 kilometres from its landing site, gathering rock samples for return to Earth. But engineering development problems with the vehicle led to severe cost overruns that threatened to break NASA's \$200 million-a-year Mars budget.

Now a far less capable rover is likely to fly on the mission, and no samples will be collected. Dropping the long-distance rover was a "considerable disappointment," says Michael Carr, a planetary scientist with the US Geological Survey in Flagstaff, Arizona.

This and other signs of trouble prompted NASA science managers to call for a fresh look at the long-term strategy for Mars exploration. A team of 30 engineers, planetary scientists, biologists and other specialists led by Charles Elachi of the Jet Propulsion Laboratory (JPL), California, has been meeting during the summer, and hopes by early September to produce a new draft "architecture" for Mars exploration. Louis Friedman, director of the California-based Planetary Society, says the group has "a lot of clever people coming up with a lot of clever ways of doing things". As a result, he says, the Mars programme is "sparkling again".

Part of the reason is a growing European involvement with the programme. Elachi's team includes representatives from France, Italy and the European Space Agency (ESA). They bring engineering and scientific expertise, and the promise of financial resources beyond what the White House and US Congress have been willing to provide. Dan McCleese, chief scientist for Mars exploration at JPL, calls this a "significant new step".

"We had, up until this study, a NASA-only programme," McCleese says. "Now we've decided to build this [new] architecture assuming international cooperation." Key to the plan would be France's provision of an Ariane 5 launch for the sample return mission in 2005, as well as a Mars-orbiting spacecraft that would receive samples from the surface (see Nature 391, 213; 1998).

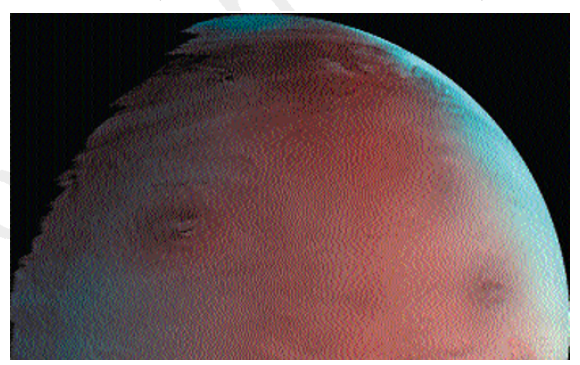

Sparkling again: international study group is bringing fresh impetus to plans for Mars missions.
The Italian Space Agency is proposing a communications satellite in Mars orbit to collect data from other spacecraft and relay them to Earth. ESA's proposed Mars Express mission, which hopes for a final go-ahead from the agency's Science Programme Committee in November and a launch in 2003, will carry an Italian-US radar system for detecting water beneath the surface of Mars.

France will also provide free 'piggyback' launches on Ariane, which can deliver additional small payloads ( 30 to 40 kilograms) to Mars at regular intervals. Elachi says these small missions - as many as four for every two-year launch opportunity - are likely to be an integral part of NASA's new plan as they could scout out sites for subsequent landers. By 2015 samples could be collected from up to six different locations on Mars.

One innovation that holds great promise is a recent proposal by JPL engineers to launch samples from the Martian surface to Mars orbit using solid-fuel rockets rather than heavier and more complicated liquidfuel rockets. If approved, the technique could dramatically reduce costs or allow more scientific equipment to be sent to Mars.

The Elachi team will not deliver its final report until late September, but scientists who have been involved in the discussions are enthusiastic about the results so far. Steven Squyres of Cornell University, whose experiments on the 2001 mission had to be scaled down because of the loss of the more capable rover, says: "I'm feeling more optimistic about this programme than I have in years."

Tony Reichhardt

\section{Ethical protection for subjects 'could stifle psychiatric research'}

[WASHINGTON] The leading US organization of medical schools is sharply criticizing a presidential commission's draft report that recommends new ethical protections for research subjects with mental health problems.

The Association of American Medical Colleges (AAMC) says the report's recommendations threaten to eliminate whole areas of psychiatric research. In a letter of 31 July to the National Bioethics Advisory Commission (NBAC), the association's president, Jordan Cohen, says the report paints an unfair picture of psychiatric researchers as disproportionately unethical. Cohen says that, by focusing on the mentally ill, the report risks stigmatizing people with mental disorders, when many other subjects can be said to have impaired capacity to consent.

The draft report, "Research involving subjects with mental disorders that may affect decisionmaking capacity," was released on 1 July. It is the product of a year of work by the 17-member commission, which is considering the adequacy of current government research protections for the mentally ill.

In the late 1970s and early 1980s, two national commissions recommended that such protections be enhanced. But the Department of Health and Human Services shelved the recommendations after researchers complained that they would hamper research. There are echoes of those complaints in the current AAMC letter.

The association objects to a recommendation that "any apparent dissent" by a research subject must be honoured. If their surrogate representatives aren't allowed to overrule patients in some cases, it says, this "could make it impossible to complete research projects in Alzheimer's disease and other conditions".

Similarly, the association attacks a recommendation that research that does not benefit subjects and that is of greater than minimal risk should be conducted only with the subject's informed consent plus the consent of a legally authorized surrogate. The AAMC says that requiring individual consent, coupled with the "vagueness" of the term "greater than minimal risk," could "effectively eliminate" research that does not benefit subjects.

But Stephen McConnell, vice-president for public policy at the Alzheimer's Association, says his group backs both NBAC recommendations. They "certainly will inhibit some research, but we will always defer to an individual," he says.

James Childress, the chairman of the NBAC subcommittee that drafted the report, declined to comment on the criticisms. He says the comments received will be taken seriously as the draft report is revised for presentation to the commission in mid-September. The text of the draft is at www.bioethics.gov.

Meredith Wadman 